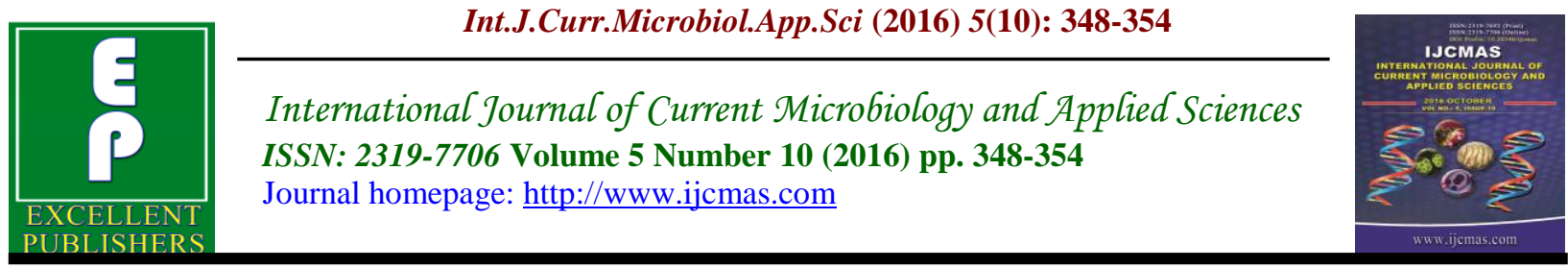

Original Research Article

http://dx.doi.org/10.20546/ijcmas.2016.510.039

\title{
Biodegradation of Pesticide using Fungi Isolated from Paddy Fields of Thanjavur District, India
}

\author{
M. Sangeetha ${ }^{1}$, K. Kanimozhi ${ }^{1}$, A. Panneerselvam ${ }^{1}$ and R. Senthil Kumar ${ }^{2}$ \\ ${ }^{1}$ P.G and Research Department of Botany and Microbiology, A.V.V.M. Sri Pushpam \\ College (Autonomous), Poondi-613503, India \\ ${ }^{2}$ Department of Microbiology, PG Extension Centre, Bharathidasan University, \\ Perambalur-621107, India \\ *Corresponding author
}

\section{A B S T R A C T}

Keywords

Pesticides,

Biodegradation,

Environment

and

Pollution.

\section{Article Info}

Accepted:

14 September 2016

Available Online:

10 October 2016
Pesticide use raises a number of environmental concerns. Over $98 \%$ of sprayed insecticides and $95 \%$ of herbicides reach a destination other than their target species, including non-target species, air, water and soil. Although they improve the quality and yield of the agricultural product but do have certain serious effect on the environment. This study focuses on development of a method to reduce the environmental burden of the pesticide by way of biodegradation. In the present study, totally twenty two fungal isolates were screened. The isolates from agricultural soils were identified as filamentous fungi belonging to the phyla Ascomycota (7 genera), Deuteromycota (2) and Zygomycota (1). Out of twenty two isolates, only two isolates were highly degrade the pesticide (chlorpyriphos) and form high level of biomass by Aspergillus fumigatus $(93.6,93.3 \%)$ and A. niger $(82.2,77.4 \%)$ respectively.

\section{Introduction}

The pesticides belong to a category of chemicals used worldwide as herbicides, insecticides, fungicides, rodenticides, molluscicides, nematicides, and plant growth regulators in order to control weeds, pests and diseases in crops as well as for health care of humans and animals. The positive aspect of application of pesticides renders enhanced crop/food productivity and drastic reduction of vector-borne diseases (Damalas, 2009 and Agrawal et al., 2010).

As a result of human activities, currently a large number of pollutants and waste are eliminated to the environment. Worldwide, more than one billion pounds of toxins are released into the air and water. Approximately $6 \times 10^{6}$ chemical compounds have been produced; annually 1,000 new products are synthesized and between 60,000 and 95,000 chemicals are commercially used (Shukla et al., 2010).

Worldwide approximately 9,000 species of insects and mites; 50,000 species of plant pathogens, and 8,000 species of weeds damage crops. Different pests such as insects and plants causing losses estimated 
in $14 \%$ and $13 \%$ respectively. Pesticides are indispensable in agricultural production. About one-third of the agricultural products are produced by using pesticides. Without pesticide application the loss of fruits, vegetables and cereals from pest injury would reach $78 \%, 54 \%$ and $32 \%$ respectively. Crop loss from pest's declines to $35 \%$ to $42 \%$ when pesticides are used (Pimentel, 2007).

Pesticides can be classified by target organisms (e.g. herbicides, insecticides, fungicides, rodenticides, and pediculicides), chemical structure (e.g. organic, inorganic, synthetic, or biological, although the distinction can sometimes blur), and physical state (e.g. gaseous) Biopesticides include microbial pesticides and biochemical pesticides. Plant-derived pesticides or "botanical", have been developing quickly. These include the pyrethroids, rotenoids, nicotinoids and a fourth group that includes strychnine and scillirosides (Johnson and Ware, 1991).

Pesticides exposure inflicts chronic and acute threats to human health. For example, long term low dose exposure to pesticides cause immune suppression, hormonal disruption, diminished intelligence, reproductive abnormalities and carcinoma (Gupta, 2004). Among most of the important problems associated with pesticides application are their possible persistence in the environment and therefore, their possible incorporation in to the food chain affect ecosystem and human beings (Shelton and Somich, 1988).

Native microorganisms from soil and sediment are capable of degrading pesticides (Eizuka et al., 2003) evaluated ipaconazole (triazole fungicide) degradation by soil microorganisms. They reported bacteria, actinomycetes and fungi were responsible for the degradation of this compound. Singh et al., (2008) isolated a native fungal strain from corn field soil able to use atrazine as source of nitrogen. The fungus degraded $44 \%$ of atrazine in 20 days.

Biodegradation that involves the capabilities of microorganisms in the removal of pollutants is the most promising, relatively efficient and cost-effective technology. Biodegradation is a process that involves the complete rupture of an organic compound in its inorganic constituents. The microbial transformation may be driven by energy needs, or a need to detoxify the pollutants, or may be fortuitous in nature (cometabolism). Because of the ubiquitous nature of microorganisms, their numbers and large biomass relative to other living organisms in the earth, wider diversity and capabilities in their catalytic mechanisms (Paul et al., 2005), and their ability to function even in the absence of oxygen and other extreme conditions the search for pollutant-degrading microorganisms, understanding their genetics and biochemistry, and developing methods for their application in the field have become an important human endeavour (Megharaj et al., 2011).

Therefore the present study is directed towards isolating the fungal species which are capable of carrying out the pesticide degradation.

\section{Materials and Methods}

\section{Collection of soil samples}

The study area is situated in Thanjavur District of Tamilnadu state (Lat. $20^{\circ} 0^{\prime}-10^{\circ}$ $23^{\prime} \mathrm{N}-\mathrm{S}$ and Long. $77^{\circ} 0^{\prime}-78^{\circ} 49^{\prime} \mathrm{E}-\mathrm{W}$ ). The present investigation was carried out by the collection and examination of soil samples from paddy fields of three different 
stations viz., station I (Kayavur), station II (Kollakadu) and station III (Pathirankottai) in Thanjavur District.

Soil samples were collected from paddy field of the three villages, viz., Kayavur, Kollakadu and Pathirankottai of Thanjavur District, Tamil Nadu (Table-1)

The soil samples were collected from grids defined by 8 columns and 5 rows. The width of the column and rows were $8 \mathrm{~m}$ and $10 \mathrm{~m}$ respectively. The soil samples were taken as cubes to a depth of $20 \mathrm{~cm}$, and the other two dimensions were $20 \mathrm{~cm}$; thus the sampled spaces were $8000 \mathrm{~cm}^{3}$. In each grid, two soil cubes were taken. The cubes were one meter apart from each other, and the midpoint was the centre of the grid.

The soil cubes were immediately placed in a plastic bag, mixed and passed through a 2 $\mathrm{mm}$ sieve, brought to the laboratory and stored at $4^{\circ} \mathrm{C}$, and then used for microbial analysis within $12 \mathrm{~h}$ of the sampling. For physico-chemical analysis, $1 \mathrm{~kg}$ of soil samples were air-dried and then sieved through a $2 \mathrm{~mm}$ sieve.

\section{Isolation of soil fungi}

The soil sample was serially diluted using distilled water. One $\mathrm{ml}$ of the diluted sample $\left(10^{3}\right.$ and $10^{4}$ dilution) was poured in to sterile Petri plates containing potato dextrose agar medium (PDA). The plates were incubated at room temperature $\left(27 \pm 2^{\circ}\right.$ C) for 7 days. Three replicates were maintained for each sample. After incubation period, the mycelial growth was observed on PD agar plates then the organism was identified by using standard methods (Walksman, 1922).

\section{Effect of pesticide}

The mycelia plugs of isolated fungi were inoculated in to potato dextrose agar medium along with different concentrations of pesticide, Chlorpyriphos $0.33 \mathrm{ml} / 100 \mathrm{ml}$ (T1), $\quad 0.38 \mathrm{ml} / 100 \mathrm{ml}$ (T2) separately and control also maintained. The plates were incubated at $27^{\circ} \mathrm{C}$ for 14 days.

After incubation, the mycelia mat was harvested, weighed using an electronic balance and to find out the wet weight of the fungal mycelium. Wet biomass of the fungal mycelium is accounted as the growth of parameter of the fungi. From the duplicate values, the mean value were derived and recorded.

Growth of the fungal isolates was calculated with the following formula

$\frac{w 1}{w 2} \times 100$

Whereas,

$\mathrm{W} 2=$ Wet weight of mycelium in control

$\mathrm{W} 1=$ Wet weight of mycelium in pesticide utilization trails.

\section{Results and Discussion}

Pesticides are usually applied simultaneously or one after another for crop production and this type of pesticide application often leads to a combined contamination of pesticide residues in the soil environment. A laboratory study was conducted to investigate the influence of chlorothalonil on chlorpyrifos degradation and its effects on bacterial, fungal, and Actinomycete soil populations (Chu et al., 2008).

Repeated application of pesticides in the same field for a certain number of years developed an active microbial population in soil with the ability to degrade determined compounds (Hernandez et al., 2008). Rohila and Salar (2012) reported that the total of 59 
fungal isolates were obtained from the analyses of 23 soil samples taken from pesticide contaminated soils through soil dilution agar plating. Thirty three fungal isolates were identified as, Aspergillus allhabadii, A. aultaceus, A. candidus A. flavus, A. fumigatus, A. nidulans, A. niger, A. ochraceus, A.oryzae, A. sclerotiorum, Aspergillus sp., A. sulphureus, A. sydowii, A. terreus, Alternaria brassicola, $A$. exserohilum turcicum, Drechslera australiensis, D. halodes, D. hawaiiensis, Drechslera sp., Humicola insolens, $H$. brevis, Fusarium acuminatum, Fusarium sp., Rhizopus sp., Torula herbarum and Ulocladium sp. The isolates were identified as filamentous fungi belonging to the class Ascomycotes (7 genera), Deuteromycotes (2) and Zygomycotes (1). Most of the fungal isolates were identified to the species level. Alternaria, Aspergillus, Drechslera, and Fusarium were predominant genera. Curvularia, Exseroholium, Humicola, Rhizopus and Torula were the most frequently isolated genera.

In the present study, totally 22 isolates were identified from all the three sampling station. Out of 22 isolates, 18 isolates were identified from Kayavur and Pathirankottai soil samples, 20 isolates were screened from Kollakadu soil samples (Table-2)

In the present study, to evaluate above mentioned fungal culture were treated with $0.33 \mathrm{ml} / 100 \mathrm{ml}$ and $0.38 \mathrm{ml} / 100 \mathrm{ml}$ concentration of Pesticide (Chlorpyriphos). Among the twenty two isolates, Aspergillus fumigatus highly degrade the pesticide and form high level of biomass $(93.6,93.3 \%)$ in both concentration $\mathrm{T} 1$ and $\mathrm{T} 2$ and next to $A$. niger $82.2,77.4 \%$ respectively. Among the twenty two isolates, five isolates were highly degrade the pesticide and form high level of mycelial biomass in T1 concentration such as Aspergillus fumigatus 93.6\%, A. repens $89.4 \%$, A. terricola $82.8 \%$, A. wentii $89.5 \%$ and A. niger $82.2 \%$ were recorded. Other isolates were degrade the pesticide and form mycelial biomass at moderate level some of them at minimum level (Table-3)

Among the twenty two isolates, Five isolates were highly degrade the pesticide and form high level of mycelial biomass in T2 concentration such as Aspergillus fumigatus $93.3 \%$, A. avensceus $81.6 \%$, A. niger $77.4 \%$, A. terreus $76.5 \%$ and Penicillium granulatum $71.8 \%$ recorded. Other isolates were degrade the pesticide and form mycelial mat in moderate level some of them at minimum level. Hussaini et al. (2013) also reported that four (4) fungal isolates were showed significant ability to carry out the degradation of selected pesticides, these cultures were identified as Aspergillus niger, Ganoderma austral, Trichosporon, Verticillium dahaliae. Aspergillus niger, has showed maximum (59\%) degradation of Endosulfan, and it has degradaed $(29 \%)$ of Lindane, it was not effective against other pesticides.

Ganoderma austral, has showed highest (61\%) degradation for Lindane whereas for Chlorpyrifos degradation was only $16 \%$. Trichosporon sp., has given highest degradation of Chlorpyrifos at 55\%, and for Endosulfan and, Lindane was $10 \%$ and $7 \%$ respectively. For Verticillium dahaliae, maximum degradation (64\%) of Chlorpyrifos, whereas for Endosulfan was $8 \%$, for Malathion was $10 \%$ and for Lindane was $10 \%$.

Similar work was reported by Thabit, et al., (2014), the chlorpyriphos degradation was not significantly altered by its combination with chlorothalonil. 
Table.1 Collection of soil sample from different irrigation paddy field of Thanjavur Dt.

\begin{tabular}{|c|c|c|}
\hline Sample no & Irrigation & Place \\
\hline 1 & Bore well & Kayavur \\
\hline 2 & River & Kollakadu \\
\hline 3 & Pond & Pathirankottai \\
\hline
\end{tabular}

Table.2 Isolation of microorganisms from the pesticide applied soil samples

\begin{tabular}{|c|l|c|c|c|}
\hline S.no & \multicolumn{1}{|c|}{ Organisms } & Kayavur & Kollakadu & Pathirankottai \\
\hline 1 & Aspergillus aureolatus & + & + & + \\
\hline 2 & A.avensceus & + & + & + \\
\hline 3 & A.arenarius & + & + & + \\
\hline 4 & A.candidus & + & + & + \\
\hline 5 & A. duricaulis & - & + & + \\
\hline 6 & A.fumigatus & + & - & + \\
\hline 7 & A.janus & + & + & + \\
\hline 8 & A.niger & + & + & + \\
\hline 9 & A.puniceus & + & + & + \\
\hline 10 & A.panamensis & + & + & + \\
\hline 11 & A.repens & + & + & + \\
\hline 12 & A.sparsus & + & + & + \\
\hline 13 & A.speluneus & - & + & + \\
\hline 14 & A.subolivaceus & + & + & + \\
\hline 15 & A.tamarii & + & + & + \\
\hline 16 & A.terreus & + & + & + \\
\hline 17 & A.terricola & + & + & + \\
\hline 18 & A.ustus & + & + & + \\
\hline 19. & A.wentii & + & + & + \\
\hline 20. & Penicillium sp. & + & + & + \\
\hline 21. & Penicillium frequentans & + & + & + \\
\hline 22. & P. granulatum & + & + & + \\
\hline & & + & + & + \\
\hline
\end{tabular}


Table.3 Effect of pesticide (Chloropyriphos $0.33 \mathrm{ml} / 100 \mathrm{ml}$ and $0.38 \mathrm{ml} / 100 \mathrm{ml}$ ) on various fungal growth

\begin{tabular}{|c|l|c|c|c|c|c|}
\hline \multirow{2}{*}{ S.no } & \multicolumn{2}{|c|}{ Name of the Species } & \multicolumn{2}{c|}{ Mycelial biomass (g) } & \multicolumn{2}{l|}{ Percentage of biomass } \\
\cline { 3 - 6 } & & Control & $\mathrm{T} 1$ & $\mathrm{~T} 2$ & $\mathrm{~T} 1$ & $\mathrm{~T} 2$ \\
\hline 1 & Aspergillus aureolatus & 3.2 & 1.7 & 0.5 & 53.1 & 15.1 \\
\hline 2 & A.avensceus & 4.9 & 4.2 & 4.0 & 76.5 & 81.6 \\
\hline 3 & A.arenarius & 6.2 & 5.1 & 4.9 & 85.7 & 25.7 \\
\hline 4 & A.candidus & 3.0 & 1.9 & 0.4 & 63.3 & 11.1 \\
\hline 5 & A.duricaulis & 2.9 & 2.1 & 1.4 & 72.4 & 48.2 \\
\hline 6 & A.fumigatus & 6.3 & 5.9 & 5.6 & 93.6 & 93.3 \\
\hline 7 & A.janus & 2.6 & 1.3 & 1.0 & 50.0 & 38.4 \\
\hline 8 & A.niger & 6.2 & 5.1 & 4.8 & 82.2 & 77.4 \\
\hline 9 & A.puniceus & 3.6 & 2.9 & 2.2 & 80.5 & 50.0 \\
\hline 10 & A.panamensis & 2.5 & 1.7 & 1.5 & 68.0 & 60.0 \\
\hline 11 & A.repens & 6.7 & 6.0 & 5.1 & 89.5 & 65.3 \\
\hline 12 & A.sparsus & 1.3 & 1.0 & 0.4 & 76.9 & 22.2 \\
\hline 13 & A.speluneus & 2.9 & 0.9 & 0.3 & 31.0 & 10.3 \\
\hline 14 & A.subolivaceus & 3.9 & 3.1 & 2.6 & 79.5 & 44.0 \\
\hline 15 & A.tamarii & 2.9 & 1.5 & 1.0 & 51.7 & 30.3 \\
\hline 16 & A.terreus & 5.9 & 3.9 & 3.6 & 66.1 & 76.5 \\
\hline 17 & A.terricola & 3.8 & 3.4 & 2.9 & 89.4 & 54.7 \\
\hline 18 & A.ustus & 1.8 & 0.5 & 0.2 & 27.7 & 4.2 \\
\hline 19 & A.wentii & 3.5 & 2.9 & 2.2 & 82.8 & 26.5 \\
\hline 20 & Penicillium sp. & 3.8 & 2.7 & 2.2 & 71.0 & 44.8 \\
\hline 21 & Penicillium frequentans & 4.7 & 3.8 & 3.0 & 80.9 & 50.8 \\
\hline 22 & P. granulatum & 3.9 & 2.6 & 2.2 & 66.6 & 71.8 \\
\hline & & & & & \\
\hline
\end{tabular}

A review of Briceno et al., (2007) showed that various bacteria and fungi present in soils has the capacity to degrade or mineralize several pesticide groups. The studies showed that addition of organic amendment and nutrients can affect mainly the adsorption, movement, and biodegradation of pesticides. Repeated application of pesticides in the same field for a certain number of years developed an active microbial population in soil with the ability to degrade determined compounds.

The present study, concluded that the pesticides when applied in field rate, do not destroy the microbial biomass, but reduce the population level. Inadequate applications of pesticides most of the sensitive beneficial microbes are eradicate by the pesticide. In this study some fungal isolates were well grew on pesticide applied media and form biomass up to $93.6 \%$. So this research was preliminarily to degrade the pesticides using native fungal isolates.

\section{References}

Agrawal, A. Pandey and R.S., Sharma, B. 2010. Water Pollution with Special Reference to Pesticide Contamination in India. J. Water Res. Protection, 2: 432448.

Briceno, G., Palma, G. and Duran, N. 2007. Influence of organic amendment on the 
biodegradation and movement of pesticides. Crit. Rev. Environ. Sci. Tech., 37: 233-271.

Chu, W. and Chan, K.H. 2003. The mechanism of the surfactant - aided soil washing system for hydrophobic and partial hydrophobic organics. Sci. Total Environ., 307: 83-92.

Damalas, C.A. 2009. Understanding benefits and risks of pesticide use. Scientific Res. Essay, 4(10): 945-949.

Eizuka, E., Ito, A. and Chida, T. 2003. Degradation of ipaconazole by microorganisms isolated by paddy soil. $J$. Pestic. Sci., 28P. 200.

Gupta, P.K. 2004. Pesticide Exposure-Indian Scene. Toxicol., 198: 83-90.

Hernandez, M., Morgante, V., Avila, M., Villalobos, P., Miralles, P., Gonzalez, M. and Seegers, M. 2008. Novel s-triazinedegrading bacteria isolated from agricultural soils of central chile for herbicide bioremediation. Electron. J. Biotechn., 11(5): 1-6.

Hussaini, S.Z., Shaker, M and Iqbal, M.A. 2013. Isolation of fungal isolates for Degradation of selected pesticide. Bulletin. Env. Pharmacol. Life. Sci., 2(4): 50-53.

Johnson, J. and Ware, W.G. 1991. Pesticide litigation manual 1992 edition. Clark Boardman Callagham Environmental Law Series, NewYork, NY.

Kaufman, T. and Edwards, E.F. 1982. Pesticide -microbe interaction effect in persistence of pesticides in soil, Proc. $5^{\text {th }}$ Intcondgr. Pesticide chem., 4: 177-182.

Megharaj, M., Ramakrishnan, B., Venkateswarlu, K., Sethunathan, N., and Naidu, R. 2011. Bioremediation approaches for organic pollutants: A critical perspective. Inter. J. Environ. Sci., 37: 1362-1375.

Paul, D., Pandey, G., Pandey, J. and Jain, R.K. 2005. Accessing microbial diversity for bioremediation and environmental restoration. Trends Biotechnol., 23: 135142.

Pimentel, D. 2007. Environmental and economic costs of the application of pesticides primarily in the United States. In: Food, Energy, and Society, Third Edition, edited by Pimentel $M$. and Pimentel D. CRC Press.

Rohilla, S.K. and Salar, R.K. 2012. Isolation and characterization of various fungal strains from Agricultural soil contaminated with pesticide. Res. J. Recent Sci., 1: 297-303.

Sanchez, S.E. and Ortiz, H.L. 2011. Riesgos yestrategias eneluso de plaguicidas. Invention, 7(14): 21-27.

Shelton, D.R. and Somich, C.J. 1988. Isolation and identification of coumaphosmetabolising bacteria from cattle dip. AppI. Environ. Microbiol., 54: 25662571.

Shukla, K.P., Singh, N.K. and Sharma, S. 2010. Bioremediation: developments, current practices and perspectives. Genet. Eng. Biotechnol. J., 3: 1-20.

Singh, S.B., Lal, S.P., Pant, S. and Kulshetra, G. 2008. Degradation of atrazine by an acclimatized soil fungal isolate. $J$. Environ. Sci. Heal. B., 43(1): 27-33.

Warcup, J.K. 1950. Effect of partial sterilization by steam or formalin on damping off of sikka spruce. Trans, $B r$. Mycol Soc., pp: 258-262.

\section{How to cite this article:}

Sangeetha, M., K. Kanimozhi, A. Panneerselvam and Senthil Kumar, R. 2016. Biodegradation of Pesticide using Fungi Isolated from Paddy Fields of Thanjavur District, India. Int.J.Curr.Microbiol.App.Sci. 5(10): 348-354. doi: http://dx.doi.org/10.20546/ijcmas.2016.510.039 